\title{
Research allocations: the influence of material and social factors
}

Published at www.cmaj.ca on July 23

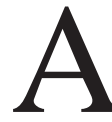
large portion of funding for health research comes from private organizations, and while some of these groups raise substantial amounts of money, others struggle to attract funds. This variance often has little to do with the effects particular diseases have on society, but rather with how savvy certain groups are in making their issues resonate with people, says Jeremy Shiffman, an associate professor of public administration at Syracuse University in New York who researches the political dynamics of health and policy-making.

In a 2009 paper, Shiffman made the case that material factors - mortality, morbidity burden, availability of costeffective interventions - do not explain why certain health issues garner widespread support while others are neglected (Bull World Health Organ 2009;87:608-13). He notes that, a decade ago, more than a third of donor funding for health went to HIV/AIDS, which accounted for only about $5 \%$ of the mortality and morbidity burden in low- and middle-income countries. Yet illnesses that killed millions more, such as pneumonia and diarrhoeal diseases, were largely ignored by donors.

Shiffman proposes that the way a health issue is framed determines the amount of resources it will attract. For instance, HIV/AIDS groups have been very successful because their issue can be framed in many ways: as a public health problem, as a development issue, as a humanitarian crisis and as a human rights issue.

"Different frames may resonate with different actors," he wrote. "A finance minister may be swayed to address an issue by a cost-effectiveness argument, an epidemiologist by the potential for public health impact and a civil society activist by a rights-based claim."

A particularly effective way of

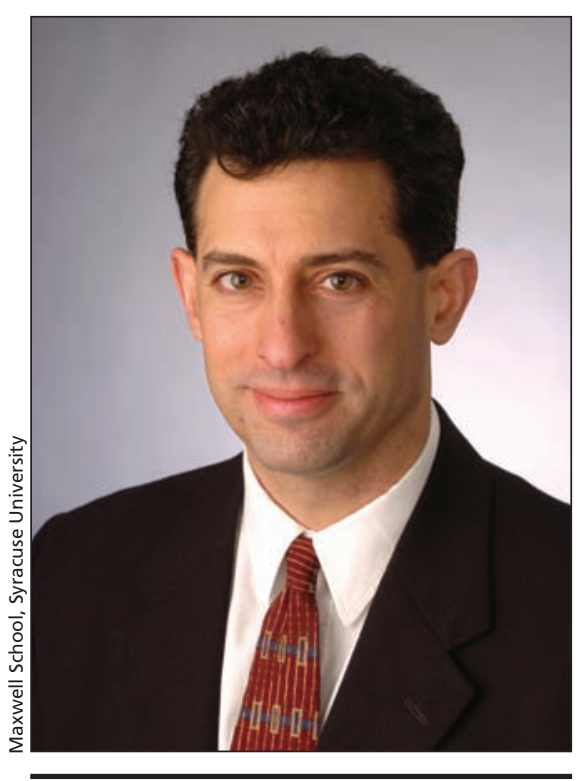

Material factors - mortality, morbidity burden, availability of cost-effective interventions - do not explain why certain health issues garner widespread support while others are neglected, says Jeremy Shiffman, who researches the political dynamics of health and policy-making.

framing a problem, as many politicians know all too well, is to portray it in as scary a light as possible. "If, like the AIDS groups, you frame your problem as a fundamental threat to society, you will alarm people, and you are going to get more resources," says Shiffman.

HIV/AIDS also receives a lot of attention because it is a chronic illness, says Shiffman. Because advocates for a health issue tend to be people directly affected by it, chronic conditions, such as diabetes and breast cancer, have an advocacy advantage. A short-term illness, such as diarrhea, can produce devastating effects but people don't define themselves as living with the condition. A chronic illness, however, tends to infiltrate an individual's identity.

"The people who have these diseases in part define themselves in terms of someone living with these diseases, and this forms a powerful advocacy constituency and rational for mobilization that you don't see with less-chronic conditions," says Shiffman.

Shiffman notes that there are many other factors that influence how much attention a health issue receives. One is the economic and political clout of the people directly affected. Middle-aged businessman, for instance, have more influence than third-world children. Another factor is an advocacy group's ability to convince people that giving them money will result in a convincing solution to the problem. Overall, though, there has been little effort put into determining why certain advocacy groups succeed while others fail.

"The study of what determines who gets attention in resource allocation in health is in its infancy," says Shiffman. "There are a lot of people who advocate but there aren't too many who study advocacy."

What is generally accepted about health advocacy, even among academics, is that human emotions will always play a large role. Health is personal, and certain health issues will resonate more with the public than others. For public funders of health research, such as the Canadian Institutes of Health Research (CIHR), this is less of an issue than for private bodies.

"That is a factor that doesn't come into play for a federal agency," says Pierre Chartrand, chief scientific officer and vice-president of research at CIHR. "People have opinions of what is more important and are more likely to give money for certain causes."

For private funding bodies, however, the public's emotional connection to a health issue - and to the group raising money to research the issue can directly affect bottom lines, says Marco Di Buono, director of research at the Heart and Stroke Foundation of 
Canada. "The affinity of the donor public toward the disease and the organization raising the money plays a huge role in determining whether that organization will raise enough money to do a lot of research or a little research," Di Buono says. - Roger Collier, CMAJ

DOI:10.1503/cmaj.109-3280
Fourth in a series on dividing the research pie.

Part 1: Subjective factors often influence outlays (www.cmaj.ca/cgi/doi/10.1503/cmaj.109 $-3238)$
Part 2: The long-standing basic/ strategic debate (www.cmaj.ca/cgi/doi /10.1503/cmaj.109-3241)

Part 3: Should societal concerns drive the research agenda?

(www.cmaj.ca/cgi/doi/10.1503/cmaj.109 $-3244)$ 